\title{
CARACTERIZAÇÃO ESTATÍSTICA DE FATORES DE RISCO PARA DESENVOLVIMENTO DO PÉ DIABÉTICO
}

\author{
Ana Claudia Barbosa Honório Ferreira ${ }^{1}$ \\ Maria Helena Baena M. Lopes ${ }^{1}$ \\ Danton Diego Ferreira ${ }^{2}$ \\ Henrique Ceretta Oliveira ${ }^{1}$ \\ ${ }^{1}$ Universidade Estadual de Campinas - UNICAMP \\ ${ }^{2}$ Universidade Federal de Lavras - UFLA
}

INTRODUÇÃO: O Diabetes Mellitus configura-se como uma epidemia mundial, traduzindo-se em um grande desafio para os sistemas de saúde de todo o mundo. O grande impacto econômico ocorre nos serviços de saúde, como consequência dos crescentes custos do tratamento da doença e, sobretudo de suas complicações. Dentre elas destaca-se o pé diabético, considerada uma complicação grave, que afeta os membros inferiores, podendo levar a ulcerações e até amputações. OBJETIVO: Identificar as variáveis de risco que se encontram presentes em pessoas com diabetes mellitus que apresentam alto risco de desenvolver o pé diabético, sem o uso de exames clínicos. MÉTODO: Pesquisa metodológica, em que foi utilizado um banco de dados composto por 54 fatores de risco para o pé diabético, investigados em 250 pessoas com diabetes. As informações foram coletadas em uma Associação de Diabéticos, e o instrumento de coleta de dados possui perguntas a respeito das condições socioeconômicas, alterações sentidas nos pés, e hábitos e atitudes com a saúde e com os pés. Através do uso de uma Rede Neural Competitiva foi construído um modelo neural capaz de dividir o banco de dados em dois grupos, denominados A e B. APROVAÇÃO NO COMITÊ DE ÉTICA EM PESQUISA: Esta pesquisa foi aprovada pelo Comitê de Ética e Pesquisa com seres humanos da Unicamp, CAAE 66815617.3.00005404. RESULTADOS: Verificou-se que o grupo $B$ foi composto por pessoas com maior número de variáveis de risco de desenvolver o pé diabético, e testes estatísticos comprovaram diferença significante entre os grupos $(95 \%$ de certeza). As variáveis que discriminam os grupos atingidos estão de acordo com os achados de outros estudos, indicando, em geral, maior risco para o pé diabético. Dados do grupo B: $66 \%$ relatam perda de sensibilidade nos pés, $69 \%$ rachaduras nos pés, $75 \%$ micose nos pés, $94,64 \%$ formigamento nos pés, 
$86,61 \%$ dormência nos pés, $70,54 \%$ dor nos pés, $66 \%$ pés edemaciados, $82 \%$ cortam as unhas dos pés de maneira errada e $78 \%$ as unhas encravam, $54 \%$ usam bolsa de agua quente nos pés. CONCLUSÃO: O sistema pode otimizar o trabalho da equipe de saúde, principalmente da enfermagem, pois realiza triagem de pessoas com diabetes mellitus, indicando aqueles com alto risco para desenvolver o pé diabético de acordo com suas atitudes e sensações, e que necessitam de acompanhamento prioritário na prevenção do pé diabético.

Palavras-chave: Diabetes mellitus. Pé diabético. Tecnologia. Grupos de risco. Rede neural artificial.

\section{Referências}

BRASIL. Ministério da Saúde. Diabetes Mellitus. Cadernos de Atenção Básica n.․ 16, Série A. Normas e Manuais Técnicos. Brasília, DF: 2006.

HAYKIN, S. Neural networks and learning machines. 3 ed. Prentice Hall: 2008.

INTERNATIONAL Working Group on the Diabetic Foot. International Consensus on the Diabetic Foot. M Wijnandts, Department of Internal Medicine, Academic Hospital Maastricht, Netherlands, fl3, 2001. 